\title{
Nanotechnology, Nanomedicine, and the Kidney
}

\author{
Peter V. Hauser ${ }^{1,2}$, Hsiao-Min Chang ${ }^{1,2}$, Norimoto Yanagawa ${ }^{1,2}$ and Morgan Hamon ${ }^{1,2, *}$ \\ 1 Department of Medicine, David Geffen School of Medicine, University of California Los Angeles, \\ Los Angeles, CA 90095, USA; pvhauser@ucla.edu (P.V.H.); hsiaominchang@mednet.ucla.edu (H.-M.C.); \\ nori@ucla.edu (N.Y.) \\ 2 Medical and Research Services, Greater Los Angeles Veterans Affairs Healthcare System at Sepulveda, \\ North Hills, CA 91343, USA \\ * Correspondence: morganhamon@ucla.edu
}

check for updates

Citation: Hauser, P.V.; Chang, H.-M.; Yanagawa, N.; Hamon, M. Nanotechnology, Nanomedicine, and the Kidney. Appl. Sci. 2021, 11, 7187. https://doi.org/10.3390/app11167187

Academic Editor: Pablo Guardia

Received: 30 June 2021

Accepted: 28 July 2021

Published: 4 August 2021

Publisher's Note: MDPI stays neutral with regard to jurisdictional claims in published maps and institutional affiliations.

Copyright: (c) 2021 by the authors. Licensee MDPI, Basel, Switzerland. This article is an open access article distributed under the terms and conditions of the Creative Commons Attribution (CC BY) license (https:// creativecommons.org/licenses/by/ $4.0 /)$.

\begin{abstract}
The kidneys are vital organs performing several essential functions. Their primary function is the filtration of blood and the removal of metabolic waste products as well as fluid homeostasis. Renal filtration is the main pathway for drug removal, highlighting the importance of this organ to the growing field of nanomedicine. The kidneys (i) have a key role in the transport and clearance of nanoparticles (NPs), (ii) are exposed to potential NPs' toxicity, and (iii) are the targets of diseases that nanomedicine can study, detect, and treat. In this review, we aim to summarize the latest research on kidney-nanoparticle interaction. We first give a brief overview of the kidney's anatomy and renal filtration, describe how nanoparticle characteristics influence their renal clearance, and the approaches taken to image and treat the kidney, including drug delivery and tissue engineering. Finally, we discuss the future and some of the challenges faced by nanomedicine.
\end{abstract}

Keywords: nanomedicine; nanotechnology; nanoparticle; kidney; renal imaging; tissue engineering; drug delivery

\section{Introduction}

Nanotechnology refers to the use, or application, of engineered macromolecules in the size range of 1-100 nanometers [1]. Materials involved range from polymers, metals, macromolecules, lipids, semiconductors, and chemicals [2,3]. Due to their small size, nanomaterials, which contain more than $50 \%$ nanoparticles (NP), can exhibit novel physical (mechanical, optical, electrical, magnetic, and thermal) [4-6] properties that can add substantial value in a wide array of applications, including medicine [7], generating the portmanteau nanomedicine. Over the last decade, nanomedicine has developed tools used in medical imaging, disease diagnosis, and therapies for the prevention and treatment of diseases such as cancer [8], diabetes [9,10], and cardiovascular diseases [10-12]. We further improved our understanding of how nanomaterials interact in a living organism, as well as their circulation, distribution, and excretion $[13,14]$. Despite the proven benefits, concerns regarding the assumed toxicity of nanomaterials persist.

The kidneys are vital organs that perform several essential functions. They generate urine, regulate blood pressure, balance electrolytes, and produce hormones. Kidneys can be damaged acutely by physical injury or nephrotoxic insults, with can lead to acute kidney injury (AKI), a clinical condition that is often reversible. Chronic kidney disease (CKD), describes a gradual injury due to acquired or congenital diseases that involve immune regulatory disorders, diabetes, hypertension, metabolic disease, or other disorders. CKD, which can lead to end-stage renal disease (ESRD), the permanent loss of kidney function, requires dialysis or kidney transplantation. Between 2015 and 2018, CKD had an overall prevalence of $14.9 \%$ in the US [15].

ESRD is a pressing issue, in 2018, in the US alone, the number of patients with ESRD was 131,636, a 2.3\% increase compared to the previous year. ESRD prevalence in 2018 was 783,925 , with $70.7 \%$ receiving dialysis and $29.3 \%$ of patients having a functioning 
transplanted kidney [15]. The leading causes for CKD and ESRD are diabetes, hypertension, and cardiovascular disease (Figure 1). Controlling the underlying conditions, can slow the progression of CKD and help to prevent ESRD.

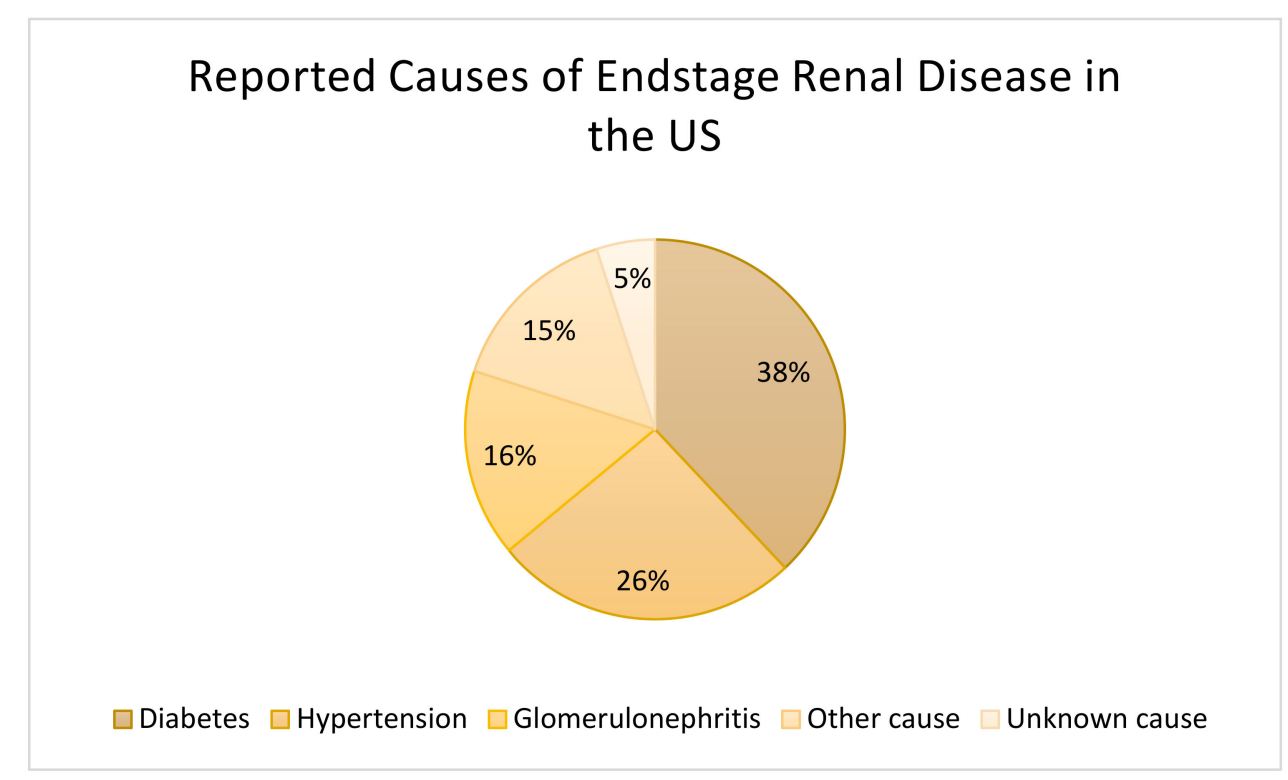

Figure 1. Causes of End-Stage Kidney Disease in the United States in 2016. Data based on patients of all ages $(n=726,331)$ [16].

The kidney is of key interest in nanotechnology and nanomedicine due to its essential functions in physiology, and further for its role and interaction in the filtration and excretion of particles used in nanomedicine therapies of distant organs. The main aspects of research in nanomedicine of the kidney are (i) the influence of the kidney on the pharmacokinetic of nanomaterials and nanodrugs, (ii) the nephrotoxic potential of nanomaterials, and (iii) the development of novel therapies to treat kidney diseases.

In recent years, kidney-excretable nanoparticles with a vastly improved signal to background ratio have been produced. It enables more precise imaging, detection, and diagnosis of renal injury, while at the same time significantly reducing nephrotoxicity by lowering the amounts of diagnostic compounds necessary. Research on the interaction of nanomaterials and the kidney has further improved our understanding of the kidney's capacity for clearance of nanomaterial, targeting of kidney cells, and the accumulation of particles in the kidney. In this review, we briefly describe the kidney's role in the elimination of nanomaterials, and we summarize the recent advances in the imaging and treatment of kidney dysfunctions using nanotechnology.

\section{Kidney}

One of the main factors influencing the pharmacokinetics of drugs and therapeutic materials is the clearance rate from the body. After their absorption, nanoparticles enter the systemic circulation, diffuse and interact with the body, and are eventually cleared by the reticuloendothelial system (RES) or the kidney. In this review, we will focus on the kidney's influence, as renal excretion is one of the most critical factors involved in the excretion of nanomedicines. For more information regarding the optimization of nanodrug pharmacokinetics, we recommend the review by Moss and Siccardi [14].

The kidneys receive 1 to $1.2 \mathrm{~L}$ of blood per minute, that is $20-25 \%$ of the cardiac output. Each kidney contains an average of one million nephrons, the basic functional unit of the kidney. Each nephron consists of the renal corpuscle, or glomerulus, the proximal, and distal tubules. Blood is transported via the renal vasculature to the glomeruli, where the primary filtrate is passed through fenestrated capillaries into the Bowman's capsule, which 
encloses the glomerulus and collects the filtrate. The filtrate is then transported to the proximal and distal renal tubules where nutrients, water, and ions are reabsorbed and waste products secreted.

From the lumen of the capillary to the inside of the Bowman's capsule, the glomerulus contains four structures that act as filters: the glycocalyx, the endothelium, the glomerular basement membrane (GBM), and the podocytes. The glycocalyx is a negatively charged layer of glycoproteins and glycolipids that protects the underlying endothelial cells and prevents large protein leakage. The endothelial layer is a fenestrated endothelium with large pores of 70-90 $\mathrm{nm}$ in diameter. The endothelial cells repose on the negatively charged GBM with pores of 2-8 nm. Its role is to prevent the filtration of large proteins and cellular components from the blood. The last filtration barrier is composed of the podocytes that sit on the urine side of the GBM. Organized as a monolayer, their interdigitating foot processes form the filtration slit sized 4 to $11 \mathrm{~nm}$. Overall, the four layers create a chargeand size-selective filtration barrier with a glomerular functional barrier's (GFB) pore size of $4.5-5 \mathrm{~nm}$ [17].

Size, shape, and charge of nanoparticles must be considered when designing nanomedicine, as they will decide between renal clearance and accumulation. For example, a positively charged nanomedicine may cross more efficiently the filtration through a negatively charged GBM and podocytes than neutral or negatively charged compounds. An overview of the potential interaction of NP with the kidney is shown in Figure 2.
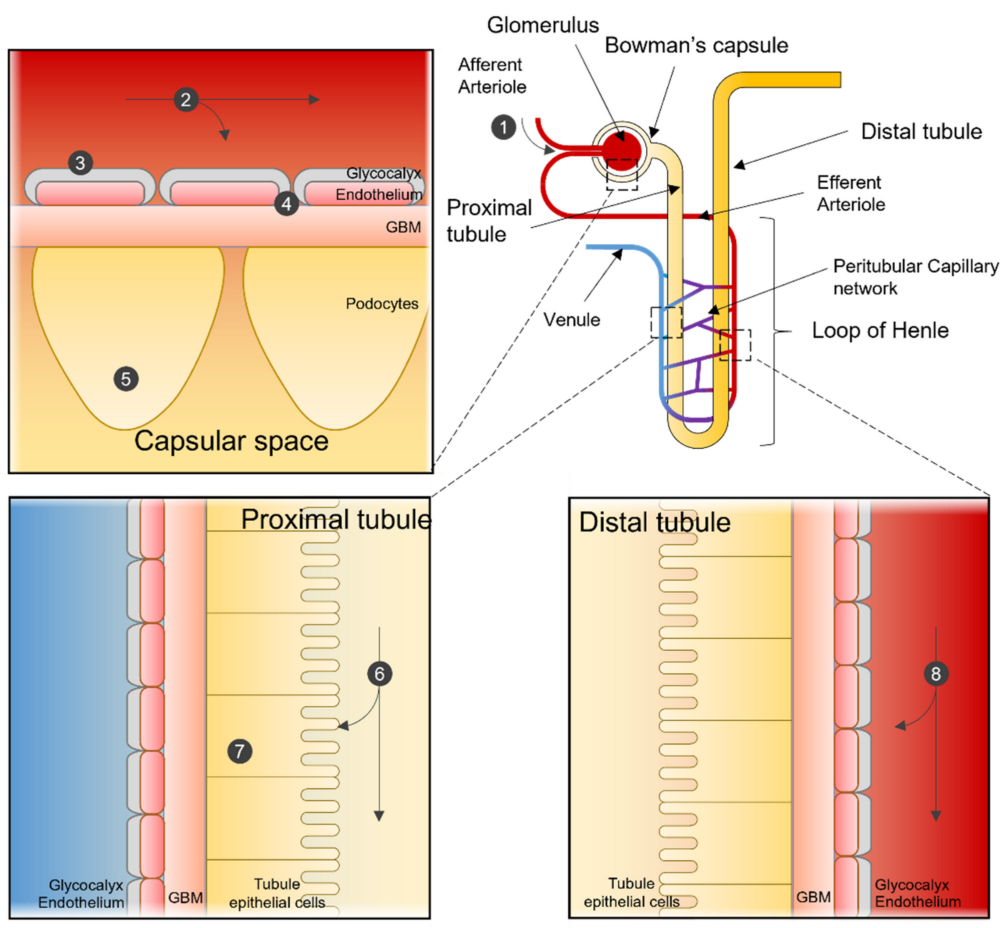

Figure 2. Nanoparticle interactions in the Nephron. Sites of interaction and potential uptake of NPs that are subject to extraction or used to target the kidney. NPs enter the kidney via the renal artery and are transported to the afferent arteriole (1). Depending on particle characteristics, NPs remain in the blood stream or are subjected to renal filtration from the blood in the glomerular capillaries (2). NPs can be designed so that renal structures, such as the glycocalyx (3), endothelial cells, or the glomerular basement membrane (4), can function in selecting NPs for filtration. After filtration, NPs can interact with podocytes in the Bowman's lumen (5). NPs in the filtrate are then transported to the proximal tubule, where they interact with proximal epithelial cells (6) and are potentially reabsorbed. Pro-drug NPs can be activated in the lysosome of proximal tubular cells (7). NPs not selected for renal filtration can interact with the renal tubular comparted after being transported from the efferent arteriole to the peritubular network (8). 


\section{Renal Clearance of Nanoparticles}

The clearance of NPs depends on several factors, such as its size [18], shape [19-22], surface charge [18,23,24], and surface treatment [25] (Figure 3).

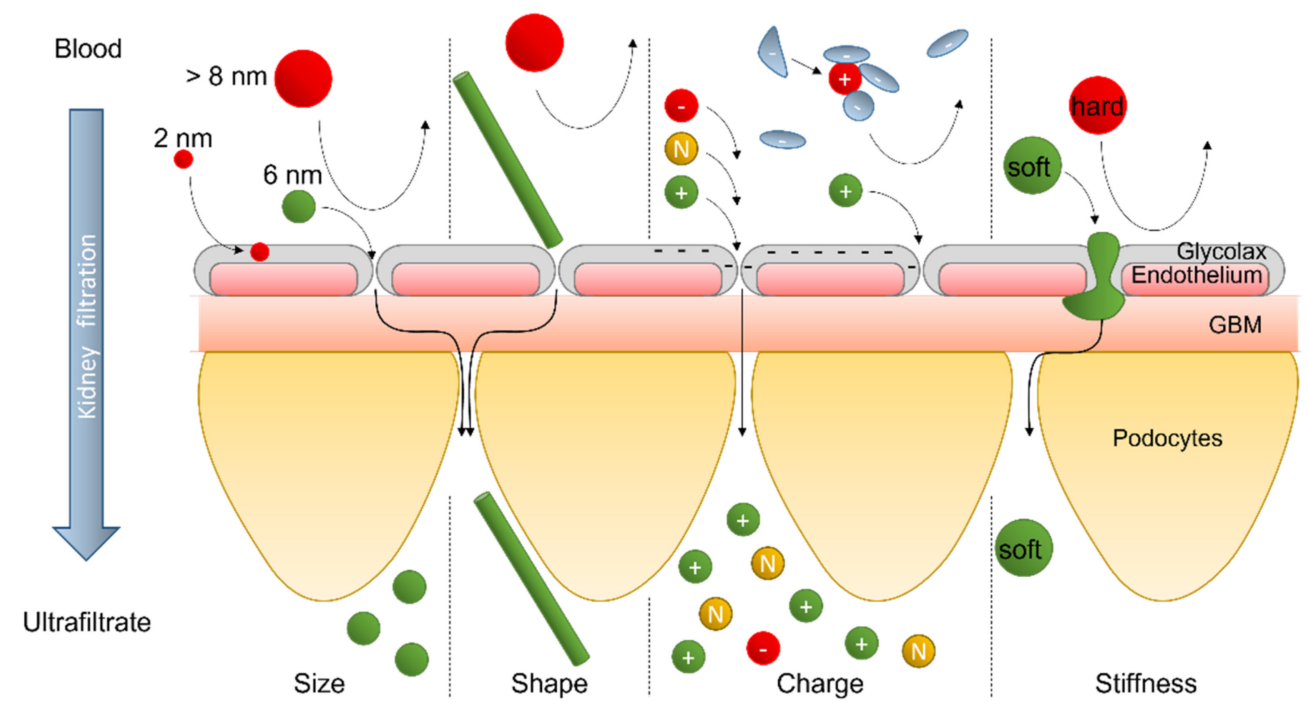

Figure 3. Nanoparticle's filtration in the glomerulus in function of NP's size, shape, charge, and stiffness.

\subsection{Size}

Size is the most obvious factor to influence NP renal clearance. For globular biomolecules, such as protein, the size-dependent threshold, i.e., the glomerular filtration regulated by the size, is generally accepted as $<5 \mathrm{~nm}$. Typically, molecules with a hydrodynamic diameter $(\mathrm{HD})<6 \mathrm{~nm}$ are filtrated, while those with an HD $>8 \mathrm{~nm}$ are not. Since NPs have properties distinct from proteins, they could exhibit a distinct renal filtration behavior [26]. Polyamidoamine (PAMAM) dendrimer-based NPs (PDBNP) and quantum dots (QD) have been used to evaluate the sizedependent threshold for NPs $[27,28]$. Similarly to conventional molecules, renal clearance studies showed that renal excretion was observed for PDBNPs and QD, with HD of $\sim 5 \mathrm{~nm}$ [18]. As expected, QD with $\mathrm{HD}>8 \mathrm{~nm}$ did not exhibit renal elimination but instead accumulation in the liver. Similar trends were observed with silica NPs and gold NPs (AuNPs), where a decrease in HD resulted in an increased renal clearance efficiency. Since the size-dependent threshold was observed from engineered NPs with HD ranging from $2 \mathrm{~nm}$ to $6 \mathrm{~nm}$, Du et al. [29] answered a fundamental question: "Is this size-dependency in the glomerular filtration still valid at an even smaller size scale?" Interestingly, they demonstrated that, in the sub-nm regime, just a few atom reductions in the gold-cluster (AuGC) size resulted in a four to nine times reduction in renal clearance efficiency because the glycocalyx trapped smaller AuGC more efficiently.

\subsection{Shape}

When fabricating NPs with an order of dimensions greater than zero (i.e., QDs), such as one-dimensional (rods and tubes) and two-dimensional (sheet) nanosystems, passive filtration does not obey the size scaling law of renal clearance, as defined in the previous chapter. For example, nanotubes with a length of over $100 \mathrm{~nm}$ can be passively filtered through the renal barrier without changing shape [20,30-32]. However, mathematical simulations suggest that glomerular filtration is possible because the blood flow is strong enough to guide carbon nanotubes (CNT) through the fenestration of the GFB along their long axis [20]. Similarly, longer, but less stiff, nanotube such as $400 \mathrm{~nm}$ long DNA tubular origami with a $7 \mathrm{~nm}$ diameter $[19,20]$, and also two-dimensional graphene oxide (1-2 nm thick and $1 \mu \mathrm{m}$ side) [33] and glutathione-coated Pd (1.8 nm thick) [34] sheets, can also be filtrated through the glomerular barrier into the urine, suggesting that NP's orientation in the blood flow is critical for the renal clearance of non-QD nanomolecules [33]. 


\subsection{Surface Charge}

The surface charge of nanosized molecules is another essential determinant of renal filtration behavior. The two main factors responsible for the effect of molecular charges are, (i) the interaction between the NP's charges and the charges within the GFB, and (ii) the HD increase due to particle adsorption of serum proteins with an opposite charge.

The influence of the molecular charge is significant for molecules in the 6 to $8 \mathrm{~nm}$ range. Studies evaluating the impact of the molecular charge on renal clearance have shown that for molecules of a similar size, clearance is faster for positively charged molecules, followed by neutral molecules, and finally negatively charged molecules, due to the presence of the negatively charge GBM in the GFB $[23,35]$.

Surface charges also influence the clearance of nanoparticles by increasing their HD over the upper limit of the GFB. For example, Choi et al., showed that purely anionic and cationic charges on the QD's surface are associated with serum protein adsorption, resulting in an increased HD of up to $15 \mathrm{~nm}$ and a reduced renal clearance [18].

\subsection{Stiffness}

The use of nanomaterials that are not rigid and inert allows for clearable NPs with a larger HD. Many "soft" and biodegradable nanosystems have been developed to facilitate renal clearance. For example, Jiang et al., developed DNA origami nanostructures of different forms [19]. Besides dimensions over at least ten times higher than the sizedependent threshold (rectangular with dimensions of $60 \times 90 \mathrm{~nm}$; triangular with $120 \mathrm{~nm}$ long sides; $400 \mathrm{~nm}$ long tube), the nanostructures exhibit a preferential renal uptake and a whole-body clearance $24 \mathrm{~h}$ after injection.

\subsection{Surface Treatment}

Recently, Wyss et al., demonstrated the possibility to increase NPs' renal clearance by surface treatment [25]. They developed glycosaminoglycan (GAG)-coated NPs to mimic the glycan surface of viruses that show renal clearance despite their large size (about $200 \mathrm{~nm}$ diameter). The GAG-coated NPs showed rapid renal clearance (74\% of the injected dose at $2 \mathrm{~h}$ ) while reducing liver accumulation. However, the authors highlighted that the excretion of intact NPs occurs via the proximal tubules but not via glomerular filtration.

\section{Nanotechnologies for Renal Imaging}

Renal imaging is a fundamental part of the clinical management of patients with renal impairment. Renal imaging strategies have evolved over the past centuries and even more over the past two decades due to modern techniques such as computed tomography, magnetic resonance imaging, and more sophisticated ultrasound techniques. The addition of nanotechnology in medical imaging has provided new solutions for the potential diagnosis of kidney disease and a better understanding of kidney biology and physiology (Figure 4).

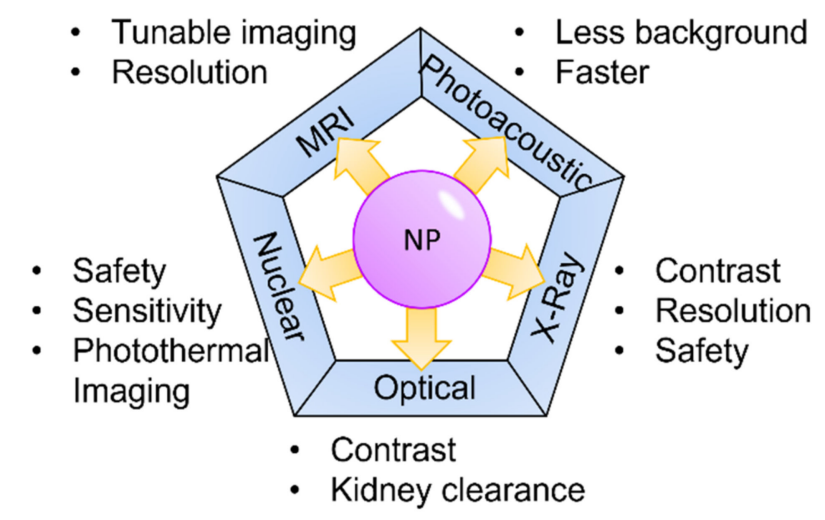

Figure 4. Nanoparticles and medical imaging. 


\subsection{Optical Imaging}

Optical imaging plays a fundamental role in biological research and clinical studies, offering an easy way to visualize events at a cellular and molecular level. Optical imaging has minimal invasiveness compared to other in vivo imaging technologies while having high sensitivity and spatiotemporal resolution.

Several NP-based methods have recently emerged to improve optical imaging contrast, including near-infrared fluorescence, chemiluminescence, and photoacoustic.

Ultrasmall luminescent metal NPs have been developed to enhance image contrast and kidney clearance. Compared to organic fluorescent dyes, these ultrasmall luminescent metal NPs have intrinsic luminescence that can be tuned with surface treatment. For example, AuNPs' emissions can differ with the density and conformation of surface thiol ligands on the metal NPs. Liu et al. [36] increased the number of zwitterionic glutathione ligands on ultrasmall gold NPs (GS-AuNPs), changing the emission center from a near-infrared $(810 \mathrm{~nm})$ to a visible wavelength $(600 \mathrm{~nm})$. Compared to using an organic fluorescent probe, GS-AuNPs also showed a 50-times enhanced contrast of kidney-to-background and increased the detection window from $0.6 \mathrm{~min}$ to $10 \mathrm{~h} \mathrm{[37],} \mathrm{dramatically} \mathrm{improving} \mathrm{the}$ usage of molecular fluorescence imaging on assessment of the stage of kidney dysfunction. In addition, Jie Zheng's group also demonstrated the possibility of controlling AuNPs' distribution in the body through surface tuning. They used polyethylene glycol thiol ligand (PEG-AuNPs) as the surface modification on NPs, extending 10-fold the blood distribution half-life from $5.4 \mathrm{~min}$ to $56.1 \mathrm{~min}$ without making significant changes on the final $24 \mathrm{~h}$ renal clearance efficiencies. Consequently, PEG-AuNPs were more efficient in targeting tumors than GS-AuNPs $[38,39]$.

Photoacoustic (PA) imaging is becoming an essential tool in renal imaging because it possesses the advantages of both optic and ultrasound imaging and can provide a greater temporal and spatial image resolution. An even better resolution has been obtained by combination with nanotechnology. For example, GS-AuNPs (here, $\left.\mathrm{Au}_{25}(\mathrm{GS})_{18}\right)$ were injected and excited by an near-infrared laser wavelength of $800 \mathrm{~nm}$, eliminating the interference from endogenous hemoglobin $(\mathrm{Hb})$ and $\mathrm{HbO}_{2}$ and providing real-time imaging. GS-AuNP PA allows to take a clear image every second and, therefore, to visualize NPs transportation in real-time from the aorta to the renal parenchyma, their renal filtration, and their elimination. The data collected can then be used to quantify the GFR in healthy and unilateral ureteral obstruction (UUO) kidneys, demonstrating the possibility of applying this technology to detect the early stage of kidney injury [40].

\subsection{X-ray}

X-ray imaging is often preferred to bypass the limitation of the penetration depth caused by light scattering and absorption that limits the use of optical imaging to visualize deep organs. NPs have been designed to improve the resolution and safety of X-ray-excited biomedical imaging. For example, Ryan et al., used QDs as probes to visualize deep organs, including kidneys [41]. They excited Cadmium telluride (CdTe) QDs with a clinical X-ray system, and a sensitive Electron Multiplying Charge Coupled Device (EM-CCD) detector was used to generate an image of the emission in the near-infrared (NIR) of 715 $\mathrm{nm}$. Moreover, a fainter image was also observed with X-ray-excited endogenous radioluminescence in biological tissue than in NIR QDs emission. Therefore, compared to the use of UV/optical/NIR as the excitation sources, X-ray excitation allowed a greater spatial image resolution of the QDs distribution in vivo while using a shorter and, therefore, safer exposure time [41]. NPs with dynamic X-ray imaging can help understand the nano-bio interactions in kidneys and detect local injury more precisely and safely at the anatomical level. Xu et al., synthesized the renal-clearable near-infrared-emitting glutathione-coated gold NPs (GS-AuNPs) and used dynamic X-ray imaging to detect the transport kinetics of GS-AuNPs in the cortex, the medulla, and the pelvis of normal and UUO kidney models [42]. Compared to conventionally used iodine agent diatrizoate meglumine (DM), 
AuNPs enhance kidney contrast due to the intense $x$-ray mass attenuation coefficients of gold and the longer retention of AuNPs in kidneys [42].

\subsection{Nuclear}

Nuclear imaging, including positron emission tomography (PET) and single-photon emission computed tomography (SPECT), is used to monitor biological processes in real time using radioisotope labeling; thus, removing the depth limitation observed in optical microscopy. However, radiations, however small, present a risk for the patient's health. Therefore, radiolabeled nanoparticles have been developed to reduce radiation doses and improve the imaging sensitivity of renal nuclear imaging. Chen et al., applied ultra-small glutathione-coated gold nanoparticles (Au-GSH) to measure organ kinetics [43]. NPs were labeled with radioactive copper-64 $\left({ }^{64} \mathrm{Cu}\right)$, which has a half-life of $12.7 \mathrm{~h}$, to form ${ }^{64} \mathrm{Cu}-\mathrm{NOTA}-\mathrm{Au}-\mathrm{GSH}$, where NOTA was the chelator. Using dynamic PET imaging, the authors could monitor the biodistribution and the elimination of ${ }^{64} \mathrm{Cu}-\mathrm{NOTA}-\mathrm{Au}-\mathrm{GSH}$ from the kidney [43]. More recently, Ni et al., synthesized renal clearable nanometersized polyoxometalate $(\mathrm{POM})$ clusters $(\sim 1 \mathrm{~nm}$ in diameter) radiolabeled with Zirconium $\left({ }^{89} \mathrm{Zr}\right)$. The formed nanoparticle ${ }^{89} \mathrm{Zr}$-POM presented various advantages. First, using PET imaging, the authors demonstrated the possibility of distinguishing the early vs. end-stage of kidney dysfunction in a UUO model [44]. In addition, POM NPs possess antioxidative properties that are useful in scavenging ROS in AKI mice, a key component of the AKI pathophysiology and a target for novel therapies [45]. Moreover, the POM cluster can self-assemble to larger nanostructures when sensing an acidic tumor microenvironment. Consequently, compared to free ${ }^{89} \mathrm{Zr}$, larger radiolabeled nanostructures were retained in tumors for up to $24 \mathrm{~h}$. Finally, POM clusters have a strong NIR adsorption and are, thus, helpful for photothermal imaging and therapy in tumors [44].

\subsection{Magnetic Resonance Imaging}

Magnetic resonance imaging (MRI) is widely used in clinical diagnosis to differentiate lesions from healthy tissue. In the latest decade, NPs have been used in combination with MRI to improve the diagnosis and treatment of renal diseases. Recently, various superparamagnetic iron oxide nanoparticles (SPIONs) have been developed as transverse relaxation time T2-weighted contrast agents. SPIONs are composed of an iron oxide core and an outer layer that can be coated with drugs and antibodies for tissue-specific drug delivery and imaging. For example, the conjugation of SPOINs with an anti-MHC class II RT1 antibody improved the contrast in renal medullary inflammation imaging [46]. In another example, Dan Ma et al., introduced a novel activable dual-mode T1/T2-weighted contrast agent, an $\mathrm{Fe}_{3} \mathrm{O}_{4} \mathrm{NP}$ cross-linked to a cystamine dihydrochloride (Cys) to form $\mathrm{Fe}_{3} \mathrm{O}_{4} /$ Cys cluster NPs. The authors demonstrated that $\mathrm{Fe}_{3} \mathrm{O}_{4} / \mathrm{Cys}$ NPs exhibit improved cellular uptake. More interestingly, the redox responsiveness of the Cys disulfide bond can be reduced under the acidic microenvironment of a tumor and caused the dissociation of $\mathrm{Fe}_{3} \mathrm{O}_{4} / \mathrm{Cys}$ clusters into single $\mathrm{Fe}_{3} \mathrm{O}_{4} \mathrm{NPs}$, thereby changing its imaging properties and allowing tumor detection [47]. In magnetic resonance angiography (MRA), an MRI exam of the blood vessels, using gadolinium-based contrast agent NPs, has reported the correlation with nephrogenic systemic fibrosis (NSF) in advanced kidney failure patient [48]. More recently, Ferumoxytol, a semisynthetic carbohydrate encapsulated SPOIN, was used in MRA to treat iron-deficiency anemia caused by CKD. Stoumpos et al., used ferumoxytol-enhanced magnetic resonance angiography (FeMRA) to obtain arteriography and venography images to assist the assessment of patients with kidney failure before being wait-listed for kidney transplantation, with no observed nephrotoxicity [49]. Using FeMRA to detect early stage kidney allograft rejection in patients with clinically manifested acute rejection, Aghighi et al., observed prolonged T2 values compared to patients without signs of rejection and infiltrating macrophages [50]. 


\subsection{Multimodal Imaging}

At the end of the last century, multimodal imaging has been developed to overcome the weaknesses of the present imaging system. For example, it is possible to overcome MRI's low sensitivity by combining it with PET imaging, and at the same time, overcoming PET's poor spatial resolution. Recently several multimodal imaging approaches have been developed to achieve high-resolution spatial images in real-time, such as Positron emission tomography-magnetic resonance imaging (PET/MRI), ultrasound/MRI, and computed tomography (CT)/MRI. Special NPs have been developed for these technologies, adding another level of improvement either by improving the image quality or providing a potential treatment to restore kidney functions. The ${ }^{64} \mathrm{Cu}$-radiolabeled $\mathrm{Fe}_{3} \mathrm{O}_{4}$-levodopa (LDOPA) NPs were designed as PET/MRI imaging probes [51]. For kidney imaging by SPECT, gamma counting, and MRI, 111In-gamma radiolabeled SPIONs were generated [52]. Polyethylene glycol incorporated- $\mathrm{Mn}^{2+}$-chelated melanin NPs radiolabeled with ${ }^{89} \mathrm{Zr}$ $\left({ }^{89} \mathrm{Zr}\right.$-MMPP) showed the ability to scavenge reactive oxygen species (ROS) and reduced oxidative stress [53]. When applied into an acute kidney injury mice model, PET/MRI bimodal imaged kidney uptake and further showed that MMPP NPs could efficiently restore renal function in the AKI mice model via antioxidative protection [53].

\section{Nanotechnology for Renal Therapy}

A diverse range of diseases injure kidneys. Injury can be the result of direct damage or as a secondary effect. Nanotechnology aims to broaden the therapy options to treat kidney damage or delay chronic injury and thereby prevent end-stage renal disease.

Therapeutic approaches can be divided into technologies that are used to (i) deliver drugs specifically to the kidney or kidney compartments, (ii) improve current renal replacement therapies, or (iii) promote the regeneration of renal tissue after injury.

\subsection{Drug Delivery}

Drug delivery is the application of pharmaceutical compounds to reach a therapeutic response. A wide array of drug delivery approaches has been developed to treat kidney diseases. They include macromolecular carriers such as liposomes, lipid particles and micelle polymers, antibodies, nanoparticle and peptide carriers, and small molecule prodrugs. Targeted delivery aims to limit the effect of a pharmacological substance on the affected tissue. Another goal is to control the manner of release, which could be to deliver the drug over a period of time or in a quick burst. Nanotechnology can be harnessed to enable targeted delivery and control drug release (Figure 5).

\subsubsection{Liposomes}

Liposomes consist of single or multiple phospholipid bilayers. They can be generated artificially using different methods and range in size from 20 to 10,000 nm [54]. The particles are actively taken up by macrophages or can passively be incorporated into a cell's membrane. Liposome particles can be loaded with bioactive molecules and are generally utilized to deliver drug molecules.

The modification of the particles allows control over vesicle distribution and the in vivo half-life. Using larger particles can help exclude the liposomes from small capillary vessels and restrict the distribution to larger blood vessels. The addition of polyethyleneglycol molecules to the lipid surface can 'hide' liposomes from macrophages and thereby increase the half-life of the particle and allow drug release over a greater period of time. The modification of liposomes with peptides holding binding domains or antibody fragments can be used to promote interaction with specific cell receptors or cell types. In addition to drugs or small molecules, liposomes can be used to deliver nucleotides and are, thus, a tool in gene therapy or gene editing strategies.

The application of liposomes in kidney-related diseases has been well described. 
Liposomes have been used as carriers in gene therapy approaches to rescue experimental congenital diseases, such as Alport's syndrome, autosomal polycystic kidney disease, or acute kidney injuries such as ureteral obstruction [55].

Van Alem et al., have demonstrated that liposomal encapsulation of prednisolone can be used for the targeted delivery of glucocorticoids to the kidney. In an experimental model for renal ischemia-reperfusion injury, they showed that liposome-encapsulated prednisolone accumulated in the inflamed kidney and increased the presence of anti-inflammatory macrophages, suggesting a reduction in proinflammatory macrophages [56]. A Mannose-PEG-DSPE (Polyethylene glycol-1, 2-Distearoyl-sn-glycero-3-phosphoethanolamine)-modified liposome was developed as a vehicle for the targeted delivery to renal glomerular cells via the Glucose Transporter (GLUT). In diabetic nephropathy, GLUT is highly expressed in glomerular mesangial cells and renal vascular smooth muscle cells. The study by Yang and colleagues demonstrated that mannose-PEG-DSPE modified liposomes can be used as a long-term vehicle for the targeted delivery in a rat model for diabetic nephropathy [57].

The low affinity of liposomes to the kidney is also used to abate the nephrotoxicity of certain drugs. For example, the liposome-encapsulated antifungal drug Amphotericin B (liposomal AmB) has a demonstrated reduced nephrotoxicity [58]. Similar approaches have been developed for the antibiotic vancomycin [59], the cytostatic drug cisplatin [60], and other platin-based anticancer drugs [61].

\subsubsection{Antibodies}

Biological enzymes, immunoglobulins, and peptide hormones are effective in targeting the kidney. Intra kidney delivery can be directed via immunoglobulin specificity or the uptake selectivity of peptides in different compartments.

Complement activation is part of the immune response and provides an initial response against infections. The dysregulation of the activated complement system is a component in many renal diseases, such as glomerulopathies, ischemia/reperfusion injury, and thrombotic microangiopathies. Macrophage antigen 1 (Mac-1) is a receptor mediating complement-activated inflammation and is expressed predominantly on macrophages infiltrating sites of tissue damage and inflammation. Mac- 1 consists of integrin aM (CD11b) and integrin 2 (CD18). Shirai et al., conjugated a CD11b antibody with silica nanoparticles. After injection in mice with experimental renal obstruction, he found that the antibody constructs bound with high affinity to the macrophages located to the area of tubular damage and interstitial inflammation [62].

Renal endothelial cells are an important part of the renal filtration apparatus. They are the target of complement activated injury during transplant-associated ischemia, leading to a delayed posttransplant function. Durigutto et al., generated an antibody specific for the complement factor C5 that was coupled with a cyclic RGD peptide [63]. The peptide RGD$4 \mathrm{C}$ has been found in a phage display assay to confer the binding to integrins expressed on endothelial cells. They found that in a rat model for I/R injury, the injected anti C5 antibody RGD conjugate was localized to the endothelial cells, where it prevented complementactivated injury. The antibody conjugate is proposed to be used in transplant medicine, where it could be used to pre-treat transplant organs from I/R associated injury.

The podocytes, or glomerular visceral epithelial cells, are the final barrier of renal filtration and their function is essential to prevent proteinuria. They are injured in a wide array of immune and non-immune mediated diseases. To target the podocytes within the glomerulus, a podocyte-specific antibody was modified by enzymatic cleavage and conjugation of a protamine molecule. Protamine exhibits a positive surface charged and, thus, can bind negatively charged nucleic acids, such a siRNA. In addition, protamine protects nucleic acids from degradation. When this antibody, loaded with siRNA specific for nephrin, was injected into a rodent, the mRNA level for nephrin was significantly reduced [64], demonstrating the specificity of the approach.

In a recent publication, $\mathrm{Li}$ et al., reported using an antibody $\mathrm{F}\left(\mathrm{ab}^{\prime}\right)_{2}$ fragment to target Plasmalemma vesicle-associated protein (PV1), an endothelial cell-specific protein that is 
a structural component of fenestrations, caveolae, and trans-endothelial channels. PV-1 expression is increased during ischemic events. They developed a high-affinity anti-PV-1 antibody $\mathrm{F}\left(\mathrm{ab}^{\prime}\right)_{2}$ fragment that showed high affinity to the kidney and assessed kidney targeting and rapid excretion [65]. They found that anti-PV-1 antibody $\mathrm{F}\left(\mathrm{ab}^{\prime}\right)_{2}$ accumulated in the kidney, and $4 \mathrm{~h}$ after injection, the serum concentration of the anti-PV-1 antibody $\mathrm{F}\left(\mathrm{ab}^{\prime}\right)_{2}$ was $40 \mathrm{x}$ lower than an unspecific isotype control antibody that underwent rapid urinary elimination. They also found that a monovalent PV-1 (Fab-C4) antibody lost its kidney binding capacity. Their findings suggest that the anti-PV-1 antibody $\mathrm{F}\left(\mathrm{ab}^{\prime}\right)_{2}$ is potentially a useful drug carried to target the tubular cells of the kidney.

\subsubsection{Protein/Peptide-Based Carrier}

During glomerular filtration, low molecular weight (LMW) proteins are excreted with the primary urine and reabsorbed by proximal tubular cells. Reabsorption by the proximal tubular cells is a receptor-mediated endocytosis. After endocytosis, proteins are transported to the lysosome and enzymatically degraded into smaller peptides. Studies using macromolecules, such as chitosan [66] and glucosamine [67], or folate [68] as carriers, have shown that these molecule carriers accumulate and release drugs specifically in the kidney.

Chitosan is a polysaccharide isolated from crustaceans and has been used in several drug delivery approaches because of its great biocompatibility and degradability. It promotes transmembrane transport across epithelial barriers and has a high affinity to the renal proximal tubular cells.

Prednisolone is a glucocorticoid drug with several applications in renal medicine. It is used to preserve renal function and control the inflammatory response in renal diseases, such as lupus nephritis and glomerulonephritis, and is used to reduce chronic allograft rejection. He et al., conjugated an LMW chitosan with prednisolone and tested this compound in rat models for a minimal change disease. They found that the chitosan-prednisolone conjugate predominantly accumulated in the kidney. The conjugate effectively reduced proteinuria in animals with nephritic diseases, and it helped normalize blood urea nitrogen (BUN), albumin, and serum creatinine [69].

Ischemia-reperfusion ( $\mathrm{I} / \mathrm{R})$ injury is the leading cause of acute kidney injury and also complicates kidney transplantation. I/R injury damages the proximal tubular cells, resulting in interstitial inflammation and the activation of tissue repair processes. Triptolide (TP) is a compound that, although beneficial in mouse models of polycystic kidney disease, has only limited therapeutic applications due to its high toxicity. A pro-drug in which triptolide is conjugated to glucosamine (TPG) exhibits significantly lower liver toxicity and appears to accumulate in the kidney [70]. Injection of TPG in a rat model of I/R injury showed that TPG accumulated in the kidney and had less toxic side effects. Most importantly, tubular tissue damage was ameliorated, and the proinflammatory cytokines were found to be reduced [67].

Folate, or vitamin B9, is a naturally occurring molecule that has recently been described to slow the decline of renal function. Sirolimus is a macrolide used as an immunosuppressant in kidney transplantation. It also blocks mTOR, a central protein kinase that controls cell growth, proliferation, and survival. In a mouse model for polycystic kidney disease, a genetic disorder that leads to ESRD, the injection of a folate-sirolimus conjugate appeared to inhibit the growth of renal cysts and, thus, slowed the progression of the disease. Compared to unconjugated sirolimus injected mice, the folate-sirolimus-treated animals showed no extrarenal effects, suggesting that the folate conjugate limited the sirolimus effect to the kidney [71].

\subsubsection{Small Molecule Pro-Drugs}

While methods of targeted delivery aim to deposit a bioactive molecule to a specific cell or tissue, pro-drugs are medications that are designed to be activated only after reaching their target [72]. This can reduce adverse side effects and increase the effectiveness of a 
drug while minimizing the total drug amount per body weight. Pro-drugs are widely used in cancer treatment, but pro-drugs have also been recently developed to deliver active compounds to the kidney.

The quinolone antibiotic ciprofloxacin is commonly used to treat urinary tract infections and is metabolized in the liver. By conjugating ciprofloxacin to a synthetic lysin-rich peptide (KKEEE)3K, Wischnjow et al., were able to redirect the ciprofloxacin from the liver to the kidney [73]. They found that the radiolabeled pro-drug accumulated entirely in the kidneys can thereby deliver the antibiotic to the bladder with high efficiency.

Urinary tract infections are often complicated by antibiotic-resistant bacteria. These bacteria widely express the enzyme $\beta$-lactamase, which inactivates $\beta$-lactam antibiotics, rendering penicillin and its derivatives ineffective. In an exquisite approach, Evans et al., created an inert pro-drug by conjugating ciprofloxacin with a molecule that can be cleaved by the bacterial $\beta$-lactamase [74]. Cleavage of cephalothin, an analog to the $\beta$-lactam antibiotic cephalosporin, activates the pro-drug bactericidal effect and selectively targets antibiotic-resistant bacteria where they accumulate.

\subsubsection{Nanoparticles}

In renal targeting with nanoparticles, particle size can be used to generally determine the target compartment of the kidney. Particles small enough to pass the glomerular filtration $(5-7 \mathrm{~nm})$ barrier can be used to target the tubular area, where they are reabsorbed. Particles sized 30-150 $\mathrm{nm}$ cannot extravasate into the primary urine and remain in circulation [75]. Maximum glomerular accumulation has been described with a particle size of $80 \mathrm{~nm}$. There are exceptions. For example, ultra-small particles $(\sim 2 \mathrm{~nm})$ are too small to pass the glycocalyx and be removed via the liver. Mesoscale nanoparticles (MNP) ( 400 $\mathrm{nm}$ ) were found in proximal tubular cells, seemingly transported there by endocytosis because at that size, they are larger than the endothelial fenestration.

Gao et al., used an LMW polycationic chitosan and formed nanoparticles with polyanionic siRNA duplexes of an approximate $450 \mathrm{~nm}$ size. When they injected the LMW chitosan nanoparticles loaded with siRNA duplexes specific for water channel aquaporin 1 (AQP1) into mice, they were able to target more than $50 \%$ of the proximal tubule epithelial cells (PTECs). Targeting of PTECs was mediated via Megalin, and targeted PTECs showed a reduced expression of AQP1. This proof of principle experiment demonstrated the potential of LMW chitosan siRNA duplex nanoparticles [76].

In a very recent study, Wang et al., demonstrated that a chitosan nanoparticle could be used for the oral delivery of the drug candidate metformin to treat polycystic kidney disease [77]. Metformin is approved for the treatment of type 2 diabetes. Recent clinical trials demonstrated that it also reduces the cyst growth in polycystic kidney disease, but that 8 -fold higher doses caused discomfort in a high number of patients, and some developed an intolerance. Wang loaded metformin into chitosan nanoparticles ( $145 \mathrm{~nm}$ diameter) to accelerate the intestine transmembrane transport and enable rapid drug uptake. They found that chitosan-encapsulated metformin showed a higher bioavailability and that mice treated with oral chitosan-metformin had a lower cyst burden than mice treated with free metformin. Blood urea, nitrogen and creatinine levels were similar to untreated mice demonstrating the absence of nephrotoxicity. This study highlights the potential of chitosan encapsulation for drugs with low oral bioavailability and a potential treatment for polycystic kidney disease.

Nanoparticles can also be used to monitor the progression of renal disease, as Bai et al., demonstrated in murine experimental Adriamycin Nephrosis, a model for human Focal Segmental Glomerulosclerosis, the main cause of adult and pediatric nephrotic syndrome [78]. The doxorubicin-derivate Adriamycin induces a podocyte injury, leading to proteinuria and, subsequently, glomerulosclerosis. Bai constructed a sensor by combining an amino headgroup gold nanoparticle (Ami-AuNP) with three fluorophore proteins.

The fluorophores fluorescein isothiocyanate-modified bovine serum albumin (BSAFITC), cyanine dye Cy5-modified $\beta$-lactoglobulin ( $\beta$-Lac-Cy5), and rhodamine B-modified 
peanut agglutinin (PNA-RhB) were electrostatically linked to Ami-AuNP. While bound to Ami-AuNP, the fluorescence of the fluorophore proteins was quenched. When protein is present in the urine, the urinary proteins compete for binding with Ami-AuNP, and the fluorophore proteins are no longer quenched and emit light. Using wavelength combinations of the three fluorescence proteins, the authors were able to correlate disease stages with specific light signals [78].

Williams and colleagues generated MNP by conjugating poly(lactic-co-glycolic acid) with polyethylene glycol (PLGA-PEG). In addition, they generated fluorescent MNP by the addition of 3,3'-diethylthiadicarbocyanine iodide (DEDC) to PLGA-PEG. They then injected the MNP intravenously and detected the nanoparticles after $30 \mathrm{~min}$ in the kidney, where they persisted for $72 \mathrm{~h}$. Renal or systemic toxicity was not observed. They also tested different total amounts of MNP. They found that at $25 \mathrm{mg} / \mathrm{kg}$, the renal specificity was maximized, while at a dose of 5 or $50 \mathrm{mg} / \mathrm{kg}$, a significant accumulation of MNP in other organs could be found [79]. These MNP, therefore, show great potential for targeted delivery of drugs to the kidney.

In an approach to treat systemic hypertension, which originates in the renal tubules and vasculature, and to treat atherosclerotic lesions, Lu et al., generated a nanoparticle transfection method for the target delivery of siRNA [80]. They developed a galactose polyethylenimine glycoprotein urethane (GPE) and used it to bind anti-angiotensinogen (AGT) siRNA. They transfected GPE-AGT siRNA nanoparticles into rats with spontaneously hypertensive rats and found AGT protein expression in the liver was significantly reduced $72 \mathrm{~h}$ after treatment. Serum concentration of AGT and the cleavage-product angiotensin II was decreased. Blood pressure dropped significantly when compared to baseline. They also found that atherosclerotic lesions were attenuated and that renal function was stable. Eleven days after the transfection, blood pressure started to rise again. The study demonstrated that GPE nanoparticles can be used to modulate the renin-angiotensin system via specific siRNA.

\section{Chelation Drugs}

Vascular calcification involves the deposition of minerals, which increases the stiffness of the arteries. It is assumed that vascular smooth muscle cells can differentiate into osteoblast-like cells or chondrocytes and deposit collagens containing minerals [81]. Hemodialysis patients and patients suffering from chronic kidney disease are at increased risk for vascular calcification, which increases their mortality and morbidity [81]. Removal of free or excess calcium and phosphorus ions from these patients can slow the calcification process.

Chelation is a chemical process used to bind minerals or metals into a complex ring structure via multiple bonds. In the body, glutathione and metallothionein function as natural chelating molecules. Supporting the natural chelation process using nanoparticles could help to support renal and cardiovascular health [82].

Ethylenediaminetetraacetic acid (EDTA) is a powerful chelating agent that can bind calcium and iron ions. Clinical studies revealed that systemic infusions of EDTA are efficient in the depletion of calcium ion levels, but that the solid systemic effect of EDTA can cause hypocalcemia in blood and bone marrow. In addition, the necessary frequent infusions make ETDA therapy hard to apply. To optimize EDTA-infusion therapy, Karamched et al., developed a nanoparticle that contained EDTA and an antibody that specifically binds to sites of arteriosclerotic damage [83]. Injection of EDTA-loaded DiR (1,1-dioctadecyl3,3,3,3-tetramethylindotricarbocyanine iodide) nanoparticle in a rat model showed that the particles delivered a minimal dose of that reduced vascular calcification in the absence of bone demineralization.

\subsubsection{Hydropolymeric Carriers}

Most experimental nanoparticle therapies are administered intravenously, complicating the treatment of chronic conditions. Tripathy et al., devised a method for the 
transdermal delivery of renal targeting nanoparticles, enabling self-administered therapy via a patch applied to the skin. Their method uses dissolvable $300 \mu \mathrm{m}$ thick silicon-based microneedles arrayed on a base of polyvinyl alcohol. The patch was then loaded with folateconjugated micelle nanoparticles consisting of DSPE-PEG2000 folate (1,2-distearoyl-snglycero-3-phosphoethanolamine-N-[folate(polyethylene glycol)-2000]) and DSPE-PEG2000 methoxy amphiphiles in different ratios. The DSPE-PEG-folate micelles were found to travel from the transdermal patch to the renal epithelial cells and deliver Rhodamin B [84].

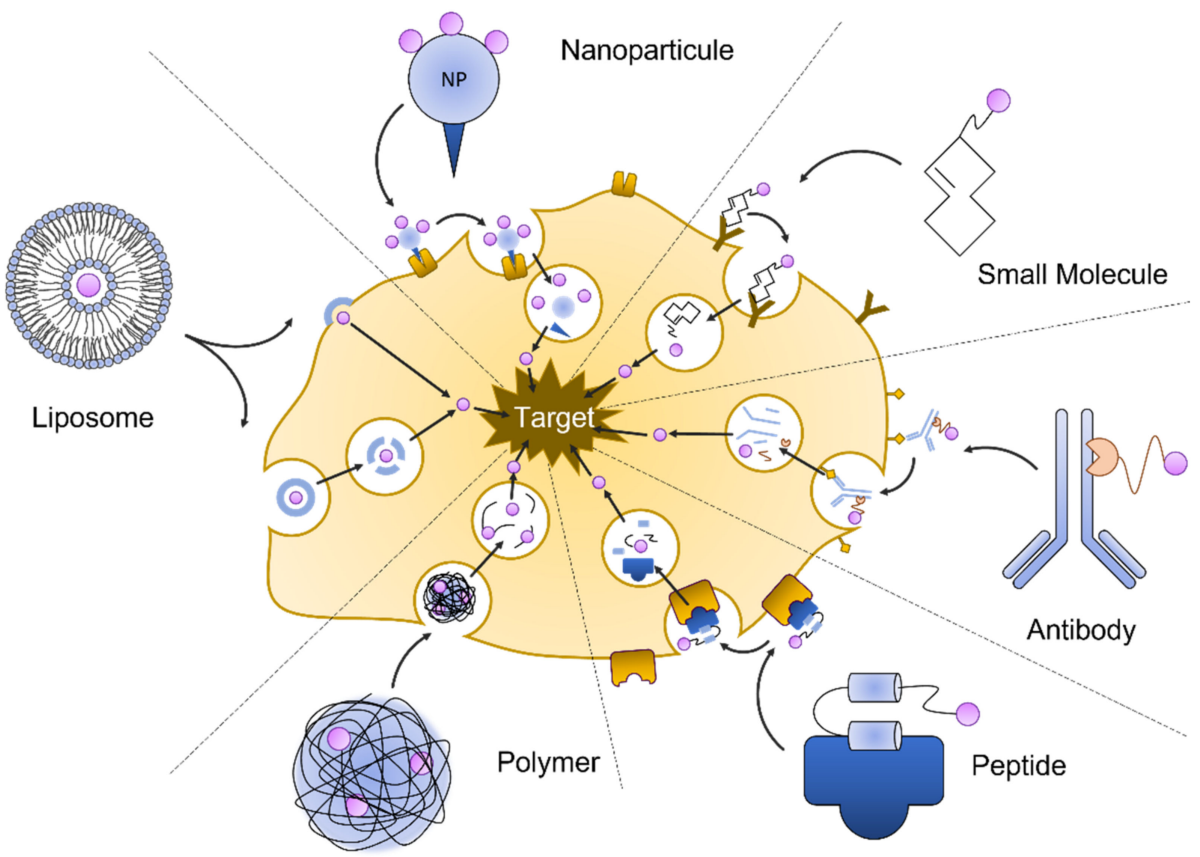

Figure 5. Nanotechnologies for drug delivery.

\subsection{Tissue Engineering}

\subsubsection{Renal Replacement Technology}

Dialysis is the most common treatment for ESRD. Blood is circulated out of the body, and during the extra-corporal phase, excess fluid is removed from blood via special membranes. Waste products and metabolites leave with the water, while the filtration membranes' aim is to retain essential proteins. Being connected to a bulky dialysis machine at home daily or at a dialysis center several times a week, the patients are limited in their range of travel. Nanotechnological solutions aim to develop wearable or implantable dialysis machines that make the patient independent from hour-long treatments on stationary equipment.

The Kidney Project at the University of California San Francisco (UCSF) is developing a fist-sized implantable artificial kidney (IAK) that performs the main function of the natural kidney [85]. In the IAK, the kidney function is carried out in two steps. First, fluid is removed from the blood by filtration through a membrane of silicon nanoparticles that generate a filtration slit of $10 \mathrm{~nm}$ [86]. In the second step, the filtrate is transported over renal tubular cells arrayed on silicon wafers. The cells reabsorb sugars, amino acids, salts, and other components valuable to the body [87]. These compounds are then transferred back to the bloodstream, and the waste fluid is removed via the bladder.

Nanotechnology is also used to improve the standard hemodialysis. Chen developed light-activated charged gold nanoparticles that exhibit a negative surface charge. When used in a dialysis filtration unit, the particles increased the efficiency of uremic toxin removal. In addition, dialysis-induced effects of coagulation activation, platelet adhesion, and thrombosis were reduced by the charged nanoparticles [88]. 


\subsubsection{Kidney Regeneration}

Rental transplantation is the treatment of choice for patients with end-stage kidney disease. However, its implementation is strongly limited by the chronic shortage of organ donors. To overcome this limitation, one solution is to regenerate the damaged kidney. In recent years, nanotechnologies have been used, combined with tissue engineering and material sciences, to develop promising applications in the field of organ regeneration.

Different nanotechnological tools are being investigated for kidney regeneration, such as carbon nanotubes [89,90], exosomes [91,92], and nanofibers [93]. This field of nanomedicine is still in its infancy but is very promising. Nanoparticles and nanomaterials could be used to either deliver biomolecules into the kidney to promote regeneration or be used as a substrate to support kidney regrowth and regeneration. For example, exosomes isolated from liver stem cells injected in AKI murine models decreased urea and creatinine levels [91]. In addition, to improve AKI kidney through functional and structural improvement, Cantaluppi et al., showed that endothelial progenitor cell-derived exosomes can stimulate pro-angiogenesis and protect the kidney from ischemia-reperfusion injury in glomerulosclerosis and tubulointerstitial fibrosis [92]. Toward the development of a supportive nanostructure for renal regeneration, biomimicking nanofibers have been developed to support the culture of human kidney-2 epithelial cells (HK-2). Cells cultured on the electrospun polymer functionalized with bioactive peptides and ureidopyrimidinone (UPy) formed a polarized cell barrier, a parallel gene expression profile for the proteins involved in the membrane transporter system, and the metabolic function of brush border enzymes [93].

\section{Future and Perspectives}

In this review, we summarized the recent advances in renal nanomedicine. We showed that the kidney is fundamental to the design of nanomedicines and that NPs are promising tools to help understand kidney functions and treat kidney diseases. However, although promising, those tools still have to be translated into clinical applications. Indeed, at the time we are writing this review, several nanoparticle-based therapies have entered clinical testing. Although currently no clinical trials are listed on clinicaltrials.gov for NPs targeting the kidney, we are expecting that the current trials for nanotechnologies targeting other organs will pave the way for the application of nanotechnologies in the renal field.

The future of nanomedicine in general, and, therefore, of renal applications, depends on various factors, mainly the capacity to control and reduce the toxicity of nanoparticles and the ability of regulators to adapt to the new technology. Similar to every drug, nanoparticles are, to a certain level, toxic [94]. For example, NPs, can translocate across biological barriers and affect secondary target organs [95], they can have adverse effects on certain cancer cells (e.g., activate cancer cells instead of damaging them) [96], agglomerate on the surface of other cells, such as endothelial cells [97] and platelets [98], or form cluster with a large HD [97], influencing their renal excretion resulting in an increased lifetime in the body. Therefore, efforts have to be dedicated to designing NPs to reduce their toxicity.

Thus far, the US Food and Drug Administration (FDA) continues to evaluate nanotechnology products on a case-by-case basis, using the combination product framework to establish the type of product and the resulting regulatory requirements [99]. However, more and more, medical, scientific, and legal authorities, such as the National Academy of Medicine [100], have repeatedly urged the FDA to correct inconsistent and inadequate classifications, as well as the combination product framework itself. In her survey, Paradise [99] identifies that, as nanomedicine progresses, the FDA faces various challenges, three of which stand out: (i) is the regulatory framework adequate in regulating this technology as distinctions usually used and their legal requirements may not be ideal? (ii) What are the potential novel risks and traditional safety and efficacy requirements appropriate? (iii) Is the labeling of nanomedicine products for consumers sufficient to inform them about nanotechnology or nanomaterials containing products [99]? To the first point, Allon et al., believe that nanomedicine does not constitute a separate, distinct, or exceptional discipline 
from an ethical standpoint and, therefore, does not necessitate special regulatory treatments to address the challenges posed by this emerging technology platform. Instead, they propose that the ethical toolbox used to address challenges utilizing conceptual models should be applied to nanomedicine as well [101]. The discussion just started, but we do not doubt that the legislators will find the adequate answer to these challenges and propose an adequate framework for the safe use of this emerging technology.

Funding: This research received no external funding.

Conflicts of Interest: The authors declare no conflict of interest.

\section{References}

1. Buzea, C.; Pacheco, I.I.; Robbie, K. Nanomaterials and Nanoparticles: Sources and Toxicity. Biointerphases 2007, 2, MR17-71. [CrossRef] [PubMed]

2. Khalid, K.; Tan, X.; Zaid, H.F.M.; Tao, Y.; Chew, C.L.; Chu, D.-T.; Lam, M.K.; Ho, Y.-C.; Lim, J.W.; Wei, L.C. Advanced in Developmental Organic and Inorganic Nanomaterial: A Review. Bioengineered 2020, 11, 328-355. [CrossRef] [PubMed]

3. Keshavarz, M.; Tan, B.; Venkatakrishnan, K. Multiplex Photoluminescent Silicon Nanoprobe for Diagnostic Bioimaging and Intracellular Analysis. Adv. Sci. 2018, 5, 1700548. [CrossRef]

4. Sadri, R.; Hosseini, M.; Kazi, S.N.; Bagheri, S.; Abdelrazek, A.H.; Ahmadi, G.; Zubir, N.; Ahmad, R.; Abidin, N.I.Z. A Facile, Bio-Based, Novel Approach for Synthesis of Covalently Functionalized Graphene Nanoplatelet Nano-Coolants toward Improved Thermo-Physical and Heat Transfer Properties. J. Colloid Interface Sci. 2018, 509, 140-152. [CrossRef]

5. Hübler, A.W.; Osuagwu, O. Digital Quantum Batteries: Energy and Information Storage in Nanovacuum Tube Arrays. Complexity 2010, 15, 48-55. [CrossRef]

6. Portela, C.M.; Vidyasagar, A.; Krödel, S.; Weissenbach, T.; Yee, D.W.; Greer, J.R.; Kochmann, D.M. Extreme Mechanical Resilience of Self-Assembled Nanolabyrinthine Materials. Proc. Natl. Acad. Sci. USA 2020, 117, 5686-5693. [CrossRef] [PubMed]

7. Kim, B.Y.S.; Rutka, J.T.; Chan, W.C.W. Nanomedicine. N. Engl. J. Med. 2010, 363, 2434-2443. [CrossRef]

8. Wilhelm, S.; Tavares, A.J.; Dai, Q.; Ohta, S.; Audet, J.; Dvorak, H.F.; Chan, W.C.W. Analysis of Nanoparticle Delivery to Tumours. Nat. Rev. Mater. 2016, 1, 16014. [CrossRef]

9. Veiseh, O.; Tang, B.C.; Whitehead, K.A.; Anderson, D.G.; Langer, R. Managing Diabetes with Nanomedicine: Challenges and Opportunities. Nat. Rev. Drug Discov. 2015, 14, 45-57. [CrossRef]

10. Luo, X.-M.; Yan, C.; Feng, Y.-M. Nanomedicine for the Treatment of Diabetes-Associated Cardiovascular Diseases and Fibrosis. Adv. Drug Deliv. Rev. 2021, 172, 234-248. [CrossRef]

11. Godin, B.; Sakamoto, J.H.; Serda, R.E.; Grattoni, A.; Bouamrani, A.; Ferrari, M. Emerging Applications of Nanomedicine for the Diagnosis and Treatment of Cardiovascular Diseases. Trends Pharm. Sci. 2010, 31, 199-205. [CrossRef]

12. Martín Giménez, V.M.; Kassuha, D.E.; Manucha, W. Nanomedicine Applied to Cardiovascular Diseases: Latest Developments. Adv. Cardiovasc. Dis. 2017, 11, 133-142. [CrossRef]

13. Nel, A.E.; Mädler, L.; Velegol, D.; Xia, T.; Hoek, E.M.V.; Somasundaran, P.; Klaessig, F.; Castranova, V.; Thompson, M. Understanding Biophysicochemical Interactions at the Nano-Bio Interface. Nat. Mater. 2009, 8, 543-557. [CrossRef]

14. Moss, D.M.; Siccardi, M. Optimizing Nanomedicine Pharmacokinetics Using Physiologically Based Pharmacokinetics Modelling. Br. J. Pharm. 2014, 171, 3963-3979. [CrossRef] [PubMed]

15. US Renal Data System. 2020 USRDS Annual Data Report: Epidemiology of Kidney Disease in the United States; National Institutes of Health, National Institute of Diabetes and Digestive and Kidney Diseases: Bethesda, MD, USA, 2020.

16. US Renal Data System. 2016 USRDS Annual Data Report: Epidemiology of Kidney Disease in the United States; National Institutes of Health, National Institute of Diabetes and Digestive and Kidney Diseases: Bethesda, MD, USA, 2016.

17. Scott, R.P.; Quaggin, S.E. Review Series: The Cell Biology of Renal Filtration. J. Cell Biol. 2015, 209, 199-210. [CrossRef]

18. Choi, H.S.; Liu, W.; Misra, P.; Tanaka, E.; Zimmer, J.P.; Itty Ipe, B.; Bawendi, M.G.; Frangioni, J.V. Renal Clearance of Quantum Dots. Nat. Biotechnol. 2007, 25, 1165-1170. [CrossRef]

19. Jiang, D.; Ge, Z.; Im, H.-J.; England, C.G.; Ni, D.; Hou, J.; Zhang, L.; Kutyreff, C.J.; Yan, Y.; Liu, Y.; et al. DNA Origami Nanostructures Can Exhibit Preferential Renal Uptake and Alleviate Acute Kidney Injury. Nat. Biomed. Eng. 2018, 2, 865-877. [CrossRef] [PubMed]

20. Ruggiero, A.; Villa, C.H.; Bander, E.; Rey, D.A.; Bergkvist, M.; Batt, C.A.; Manova-Todorova, K.; Deen, W.M.; Scheinberg, D.A.; McDevitt, M.R. Paradoxical Glomerular Filtration of Carbon Nanotubes. Proc. Natl. Acad. Sci. USA 2010, 107, 12369-12374. [CrossRef] [PubMed]

21. Singh, H.; Du, J.; Singh, P.; Yi, T.H. Ecofriendly Synthesis of Silver and Gold Nanoparticles by Euphrasia Officinalis Leaf Extract and Its Biomedical Applications. Artif. Cells Nanomed. Biotechnol. 2018, 46, 1163-1170. [CrossRef]

22. Black, K.C.L.; Wang, Y.; Luehmann, H.P.; Cai, X.; Xing, W.; Pang, B.; Zhao, Y.; Cutler, C.S.; Wang, L.V.; Liu, Y.; et al. Radioactive 198Au-Doped Nanostructures with Different Shapes for in Vivo Analyses of Their Biodistribution, Tumor Uptake, and Intratumoral Distribution. ACS Nano 2014, 8, 4385-4394. [CrossRef] 
23. Deen, W.M.; Lazzara, M.J.; Myers, B.D. Structural Determinants of Glomerular Permeability. Am. J. Physiol. Ren. Physiol. 2001, 281, F579-F596. [CrossRef]

24. Kobayashi, H.; Le, N.; Kim, I.S.; Kim, M.K.; Pie, J.E.; Drumm, D.; Paik, D.S.; Waldmann, T.A.; Paik, C.H.; Carrasquillo, J.A. The Pharmacokinetic Characteristics of Glycolated Humanized Anti-Tac Fabs Are Determined by Their Isoelectric Points. Cancer Res. 1999, 59, 422-430.

25. Wyss, P.P.; Lamichhane, S.P.; Abed, A.; Vonwil, D.; Kretz, O.; Huber, T.B.; Sarem, M.; Shastri, V.P. Renal Clearance of Polymeric Nanoparticles by Mimicry of Glycan Surface of Viruses. Biomaterials 2020, 230, 119643. [CrossRef]

26. Wiener, E.C.; Brechbiel, M.W.; Brothers, H.; Magin, R.L.; Gansow, O.A.; Tomalia, D.A.; Lauterbur, P.C. Dendrimer-Based Metal Chelates: A New Class of Magnetic Resonance Imaging Contrast Agents. Magn. Reson. Med. 1994, 31, 1-8. [CrossRef]

27. Kobayashi, H.; Brechbiel, M.W. Dendrimer-Based Nanosized MRI Contrast Agents. Curr. Pharm. Biotechnol. 2004, 5, 539-549. [CrossRef] [PubMed]

28. Kobayashi, H.; Brechbiel, M.W. Nano-Sized MRI Contrast Agents with Dendrimer Cores. Adv. Drug Deliv. Rev. 2005, 57, 2271-2286. [CrossRef] [PubMed]

29. Du, B.; Jiang, X.; Das, A.; Zhou, Q.; Yu, M.; Jin, R.; Zheng, J. Glomerular Barrier Behaves as an Atomically Precise Bandpass Filter in a Sub-Nanometre Regime. Nat. Nanotechnol. 2017, 12, 1096-1102. [CrossRef]

30. Lacerda, L.; Soundararajan, A.; Singh, R.; Pastorin, G.; Al-Jamal, K.T.; Turton, J.; Frederik, P.; Herrero, M.A.; Li, S.; Bao, A.; et al. Dynamic Imaging of Functionalized Multi-Walled Carbon Nanotube Systemic Circulation and Urinary Excretion. Adv. Mater. 2008, 20, 225-230. [CrossRef]

31. Lacerda, L.; Ali-Boucetta, H.; Herrero, M.A.; Pastorin, G.; Bianco, A.; Prato, M.; Kostarelos, K. Tissue Histology and Physiology Following Intravenous Administration of Different Types of Functionalized Multiwalled Carbon Nanotubes. Nanomedicine 2008, 3, 149-161. [CrossRef]

32. Lacerda, L.; Herrero, M.A.; Venner, K.; Bianco, A.; Prato, M.; Kostarelos, K. Carbon-Nanotube Shape and Individualization Critical for Renal Excretion. Small 2008, 4, 1130-1132. [CrossRef] [PubMed]

33. Jasim, D.A.; Murphy, S.; Newman, L.; Mironov, A.; Prestat, E.; McCaffrey, J.; Ménard-Moyon, C.; Rodrigues, A.F.; Bianco, A.; Haigh, S.; et al. The Effects of Extensive Glomerular Filtration of Thin Graphene Oxide Sheets on Kidney Physiology. ACS Nano 2016, 10, 10753-10767. [CrossRef]

34. Tang, S.; Chen, M.; Zheng, N. Sub-10-Nm Pd Nanosheets with Renal Clearance for Efficient near-Infrared Photothermal Cancer Therapy. Small 2014, 10, 3139-3144. [CrossRef]

35. Ohlson, M.; Sörensson, J.; Haraldsson, B. A Gel-Membrane Model of Glomerular Charge and Size Selectivity in Series. Am. J. Physiol. Ren. Physiol. 2001, 280, F396-F405. [CrossRef]

36. Liu, J.; Duchesne, P.N.; Yu, M.; Jiang, X.; Ning, X.; Vinluan, R.D.; Zhang, P.; Zheng, J. Luminescent Gold Nanoparticles with Size-Independent Emission. Angew. Chem. Int. Ed. Engl. 2016, 55, 8894-8898. [CrossRef]

37. Yu, M.; Liu, J.; Ning, X.; Zheng, J. High-Contrast Noninvasive Imaging of Kidney Clearance Kinetics Enabled by Renal Clearable Nanofluorophores. Angew. Chem. Int. Ed. Engl. 2015, 54, 15434-15438. [CrossRef]

38. Liu, J.; Yu, M.; Ning, X.; Zhou, C.; Yang, S.; Zheng, J. PEGylation and Zwitterionization: Pros and Cons in the Renal Clearance and Tumor Targeting of near-IR-Emitting Gold Nanoparticles. Angew. Chem. Int. Ed. Engl. 2013, 52, 12572-12576. [CrossRef] [PubMed]

39. Yu, M.; Zheng, J. Clearance Pathways and Tumor Targeting of Imaging Nanoparticles. ACS Nano 2015, 9, 6655-6674. [CrossRef] [PubMed]

40. Jiang, X.; Du, B.; Tang, S.; Hsieh, J.-T.; Zheng, J. Photoacoustic Imaging of Nanoparticle Transport in the Kidneys at High Temporal Resolution. Angew. Chem. Int. Ed. Engl. 2019, 58, 5994-6000. [CrossRef]

41. Ryan, S.G.; Butler, M.N.; Adeyemi, S.S.; Kalber, T.; Patrick, P.S.; Zaw Thin, M.; Harrison, I.F.; Stuckey, D.J.; Pule, M.; Lythgoe, M.F. Imaging of X-Ray-Excited Emissions from Quantum Dots and Biological Tissue in Whole Mouse. Sci. Rep. 2019, 9, 19223. [CrossRef] [PubMed]

42. Xu, J.; Yu, M.; Carter, P.; Hernandez, E.; Dang, A.; Kapur, P.; Hsieh, J.-T.; Zheng, J. In Vivo X-Ray Imaging of Transport of Renal Clearable Gold Nanoparticles in the Kidneys. Angew. Chem. Int. Ed. Engl. 2017, 56, 13356-13360. [CrossRef]

43. Chen, F.; Goel, S.; Hernandez, R.; Graves, S.A.; Shi, S.; Nickles, R.J.; Cai, W. Dynamic Positron Emission Tomography Imaging of Renal Clearable Gold Nanoparticles. Small 2016, 12, 2775-2782. [CrossRef]

44. Ni, D.; Jiang, D.; Im, H.-J.; Valdovinos, H.F.; Yu, B.; Goel, S.; Barnhart, T.E.; Huang, P.; Cai, W. Radiolabeled Polyoxometalate Clusters: Kidney Dysfunction Evaluation and Tumor Diagnosis by Positron Emission Tomography Imaging. Biomaterials 2018, 171, 144-152. [CrossRef]

45. Ni, D.; Jiang, D.; Kutyreff, C.J.; Lai, J.; Yan, Y.; Barnhart, T.E.; Yu, B.; Im, H.-J.; Kang, L.; Cho, S.Y.; et al. Molybdenum-Based Nanoclusters Act as Antioxidants and Ameliorate Acute Kidney Injury in Mice. Nat. Commun. 2018, 9, 5421. [CrossRef]

46. Hultman, K.L.; Raffo, A.J.; Grzenda, A.L.; Harris, P.E.; Brown, T.R.; O’Brien, S. Magnetic Resonance Imaging of Major Histocompatibility Class II Expression in the Renal Medulla Using Immunotargeted Superparamagnetic Iron Oxide Nanoparticles. ACS Nano 2008, 2, 477-484. [CrossRef]

47. Ma, D.; Shi, M.; Li, X.; Zhang, J.; Fan, Y.; Sun, K.; Jiang, T.; Peng, C.; Shi, X. Redox-Sensitive Clustered Ultrasmall Iron Oxide Nanoparticles for Switchable T2/T1-Weighted Magnetic Resonance Imaging Applications. Bioconjug. Chem. 2020, 31, 352-359. [CrossRef] 
48. Collidge, T.A.; Thomson, P.C.; Mark, P.B.; Traynor, J.P.; Jardine, A.G.; Morris, S.T.W.; Simpson, K.; Roditi, G.H. GadoliniumEnhanced MR Imaging and Nephrogenic Systemic Fibrosis: Retrospective Study of a Renal Replacement Therapy Cohort. Radiology 2007, 245, 168-175. [CrossRef]

49. Stoumpos, S.; Hennessy, M.; Vesey, A.T.; Radjenovic, A.; Kasthuri, R.; Kingsmore, D.B.; Mark, P.B.; Roditi, G. FerumoxytolEnhanced Magnetic Resonance Angiography for the Assessment of Potential Kidney Transplant Recipients. Eur. Radiol. 2018, 28, 115-123. [CrossRef] [PubMed]

50. Aghighi, M.; Pisani, L.; Theruvath, A.J.; Muehe, A.M.; Donig, J.; Khan, R.; Holdsworth, S.J.; Kambham, N.; Concepcion, W.; Grimm, P.C.; et al. Ferumoxytol Is Not Retained in Kidney Allografts in Patients Undergoing Acute Rejection. Mol. Imaging Biol. 2018, 20, 139-149. [CrossRef] [PubMed]

51. Thomas, G.; Boudon, J.; Maurizi, L.; Moreau, M.; Walker, P.; Severin, I.; Oudot, A.; Goze, C.; Poty, S.; Vrigneaud, J.-M.; et al. Innovative Magnetic Nanoparticles for PET/MRI Bimodal Imaging. ACS Omega 2019, 4, 2637-2648. [CrossRef] [PubMed]

52. Gómez-Vallejo, V.; Puigivila, M.; Plaza-García, S.; Szczupak, B.; Piñol, R.; Murillo, J.L.; Sorribas, V.; Lou, G.; Veintemillas, S.; Ramos-Cabrer, P.; et al. PEG-Copolymer-Coated Iron Oxide Nanoparticles That Avoid the Reticuloendothelial System and Act as Kidney MRI Contrast Agents. Nanoscale 2018, 10, 14153-14164. [CrossRef] [PubMed]

53. Sun, T.; Jiang, D.; Rosenkrans, Z.T.; Ehlerding, E.B.; Ni, D.; Qi, C.; Kutyreff, C.J.; Barnhart, T.E.; Engle, J.W.; Huang, P.; et al. A Melanin-Based Natural Antioxidant Defense Nanosystem for Theranostic Application in Acute Kidney Injury. Adv. Funct. Mater. 2019, 29. [CrossRef] [PubMed]

54. Alavi, M.; Karimi, N.; Safaei, M. Application of Various Types of Liposomes in Drug Delivery Systems. Adv. Pharm. Bull. 2017, 7, 3-9. [CrossRef] [PubMed]

55. Lai, L.W.; Moeckel, G.W.; Lien, Y.H. Kidney-Targeted Liposome-Mediated Gene Transfer in Mice. Gene Ther. 1997, 4, 426-431. [CrossRef] [PubMed]

56. van Alem, C.M.A.; Boonstra, M.; Prins, J.; Bezhaeva, T.; van Essen, M.F.; Ruben, J.M.; Vahrmeijer, A.L.; van der Veer, E.P.; de Fijter, J.W.; Reinders, M.E.; et al. Local Delivery of Liposomal Prednisolone Leads to an Anti-Inflammatory Profile in Renal Ischaemia-Reperfusion Injury in the Rat. Nephrol. Dial. Transplant. 2018, 33, 44-53. [CrossRef] [PubMed]

57. Yang, S.; Lin, H.; Yang, H. Study of the Target Effect of Mannose Modified Liposomes on Diabetic Rat Kidney Based on GLUT. J. Drug Deliv. Sci. Technol. 2020, 55, 101409. [CrossRef]

58. Faustino, C.; Pinheiro, L. Lipid Systems for the Delivery of Amphotericin B in Antifungal Therapy. Pharmaceutics 2020, 12, 29. [CrossRef] [PubMed]

59. Liu, J.; Wang, Z.; Li, F.; Gao, J.; Wang, L.; Huang, G. Liposomes for Systematic Delivery of Vancomycin Hydrochloride to Decrease Nephrotoxicity: Characterization and Evaluation. Asian J. Pharm. Sci. 2015, 10, 212-222. [CrossRef]

60. Stathopoulos, G.P. Liposomal Cisplatin: A New Cisplatin Formulation. Anticancer Drugs 2010, 21, 732-736. [CrossRef]

61. El-Shafie, S.; Fahmy, S.A.; Ziko, L.; Elzahed, N.; Shoeib, T.; Kakarougkas, A. Encapsulation of Nedaplatin in Novel PEGylated Liposomes Increases Its Cytotoxicity and Genotoxicity against A549 and U2OS Human Cancer Cells. Pharmaceutics 2020, 12, 863. [CrossRef] [PubMed]

62. Shirai, T.; Kohara, H.; Tabata, Y. Inflammation Imaging by Silica Nanoparticles with Antibodies Orientedly Immobilized. J. Drug Target. 2012, 20, 535-543. [CrossRef]

63. Durigutto, P.; Sblattero, D.; Biffi, S.; De Maso, L.; Garrovo, C.; Baj, G.; Colombo, F.; Fischetti, F.; Di Naro, A.F.; Tedesco, F.; et al. Targeted Delivery of Neutralizing Anti-C5 Antibody to Renal Endothelium Prevents Complement-Dependent Tissue Damage. Front. Immunol. 2017, 8, 1093. [CrossRef] [PubMed]

64. Hauser, P.V.; Pippin, J.W.; Kaiser, C.; Krofft, R.D.; Brinkkoetter, P.T.; Hudkins, K.L.; Kerjaschki, D.; Reiser, J.; Alpers, C.E.; Shankland, S.J. Novel SiRNA Delivery System to Target Podocytes in Vivo. PLoS ONE 2010, 5, e9463. [CrossRef]

65. Li, Q.; Peterson, N.; Hanna, R.N.; Kuszpit, K.; White, J.; Allen, K.L.; Barnes, A.; Rickert, K.W.; Shan, L.; Wu, H.; et al. Antibody Fragment $\mathrm{F}\left(\mathrm{Ab}^{\prime}\right)(2)$ Targeting Caveolae-Associated Protein PV1 for Selective Kidney Targeting and Retention. Mol. Pharm. 2020, 17, 507-516. [CrossRef]

66. Sutthasupha, P.; Lungkaphin, A. The Potential Roles of Chitosan Oligosaccharide in Prevention of Kidney Injury in Obese and Diabetic Conditions. Food Funct. 2020, 11, 7371-7388. [CrossRef] [PubMed]

67. Fu, Y.; Lin, Q.; Gong, T.; Sun, X.; Zhang, Z.-R. Renal-Targeting Triptolide-Glucosamine Conjugate Exhibits Lower Toxicity and Superior Efficacy in Attenuation of Ischemia/Reperfusion Renal Injury in Rats. Acta Pharm. Sin. 2016, 37, 1467-1480. [CrossRef] [PubMed]

68. Huang, C.; Zeng, T.; Li, J.; Tan, L.; Deng, X.; Pan, Y.; Chen, Q.; Li, A.; Hu, J. Folate Receptor-Mediated Renal-Targeting Nanoplatform for the Specific Delivery of Triptolide to Treat Renal Ischemia/Reperfusion Injury. ACS Biomater. Sci. Eng. 2019, 5, 2877-2886. [CrossRef]

69. He, X.; Yuan, Z.; Wu, X.; Xu, C.; Li, W. Low Molecular Weight Hydroxyethyl Chitosan-Prednisolone Conjugate for Renal Targeting Therapy: Synthesis, Characterization and in Vivo Studies. Theranostics 2012, 2, 1054-1063. [CrossRef]

70. Zhou, P.; Sun, X.; Gong, T.; Zhang, Z.; Zhang, L. Conjugating Glucosamine to Triptolide to Enhance Its Protective Effect against Renal Ischemia-Reperfusion Injury and Reduce Its Toxicity. J. Drug Target. 2014, 22, 200-210. [CrossRef]

71. Kipp, K.R.; Kruger, S.L.; Schimmel, M.F.; Parker, N.; Shillingford, J.M.; Leamon, C.P.; Weimbs, T. Comparison of Folate-Conjugated Rapamycin versus Unconjugated Rapamycin in an Orthologous Mouse Model of Polycystic Kidney Disease. Am. J. Physiol. Ren. Physiol. 2018, 315, F395-F405. [CrossRef] 
72. Yang, B.; Gao, J.; Pei, Q.; Xu, H.; Yu, H. Engineering Prodrug Nanomedicine for Cancer Immunotherapy. Adv. Sci. 2020, 7, 2002365. [CrossRef]

73. Wischnjow, A.; Sarko, D.; Janzer, M.; Kaufman, C.; Beijer, B.; Brings, S.; Haberkorn, U.; Larbig, G.; Kübelbeck, A.; Mier, W. Renal Targeting: Peptide-Based Drug Delivery to Proximal Tubule Cells. Bioconjug. Chem. 2016, 27, 1050-1057. [CrossRef] [PubMed]

74. Evans, L.E.; Krishna, A.; Ma, Y.; Webb, T.E.; Marshall, D.C.; Tooke, C.L.; Spencer, J.; Clarke, T.B.; Armstrong, A.; Edwards, A.M. Exploitation of Antibiotic Resistance as a Novel Drug Target: Development of a $\beta$-Lactamase-Activated Antibacterial Prodrug. J. Med. Chem. 2019, 62, 4411-4425. [CrossRef] [PubMed]

75. Kamaly, N.; He, J.C.; Ausiello, D.A.; Farokhzad, O.C. Nanomedicines for Renal Disease: Current Status and Future Applications. Nat. Rev. Nephrol. 2016, 12, 738-753. [CrossRef] [PubMed]

76. Gao, S.; Hein, S.; Dagnæs-Hansen, F.; Weyer, K.; Yang, C.; Nielsen, R.; Christensen, E.I.; Fenton, R.A.; Kjems, J. Megalin-Mediated Specific Uptake of Chitosan/SiRNA Nanoparticles in Mouse Kidney Proximal Tubule Epithelial Cells Enables AQP1 Gene Silencing. Theranostics 2014, 4, 1039-1051. [CrossRef]

77. Wang, J.; Chin, D.; Poon, C.; Mancino, V.; Pham, J.; Li, H.; Ho, P.-Y.; Hallows, K.R.; Chung, E.J. Oral Delivery of Metformin by Chitosan Nanoparticles for Polycystic Kidney Disease. J. Control. Release 2021, 329, 1198-1209. [CrossRef] [PubMed]

78. Bai, X.; Yu, X.; Zhang, R.; Zhang, Y.; Hu, Y.; Zhao, L.; Zhang, M.; Tian, J.; Yu, B.-Y. Protein/Gold Nanoparticle-Based Sensors for Monitoring the Progression of Adriamycin Nephropathy. ACS Appl. Nano Mater. 2021. [CrossRef]

79. Williams, R.M.; Shah, J.; Tian, H.S.; Chen, X.; Geissmann, F.; Jaimes, E.A.; Heller, D.A. Selective Nanoparticle Targeting of the Renal Tubules. Hypertension 2018, 71, 87-94. [CrossRef]

80. Lu, P.; Yuan, L.; Wang, Y.; Du, Q.; Sheng, J. Effect of GPE-AGT Nanoparticle ShRNA Transfection System Mediated RNAi on Early Atherosclerotic Lesion. Int. J. Clin. Exp. Pathol. 2012, 5, 698-706. [PubMed]

81. Moe, S.M.; Chen, N.X. Mechanisms of Vascular Calcification in Chronic Kidney Disease. J. Am. Soc. Nephrol. 2008, 19, 213-216. [CrossRef]

82. Sears, M.E. Chelation: Harnessing and Enhancing Heavy Metal Detoxification-a Review. Sci. World J. 2013, 2013, 219840. [CrossRef] [PubMed]

83. Karamched, S.R.; Nosoudi, N.; Moreland, H.E.; Chowdhury, A.; Vyavahare, N.R. Site-Specific Chelation Therapy with EDTALoaded Albumin Nanoparticles Reverses Arterial Calcification in a Rat Model of Chronic Kidney Disease. Sci. Rep. 2019, 9, 2629. [CrossRef] [PubMed]

84. Tripathy, N.; Wang, J.; Tung, M.; Conway, C.; Chung, E.J. Transdermal Delivery of Kidney-Targeting Nanoparticles Using Dissolvable Microneedles. Cell Mol. Bioeng. 2020, 13, 475-486. [CrossRef] [PubMed]

85. Salani, M.; Roy, S.; Fissell, W.H. 4th Innovations in Wearable and Implantable Artificial Kidneys. Am. J. Kidney Dis. 2018, 72, 745-751. [CrossRef] [PubMed]

86. Feinberg, B.J.; Hsiao, J.C.; Park, J.; Zydney, A.L.; Fissell, W.H.; Roy, S. Slit Pores Preferred over Cylindrical Pores for High Selectivity in Biomolecular Filtration. J. Colloid Interface Sci. 2018, 517, 176-181. [CrossRef]

87. Wilson, M.H.; Veach, R.A.; Luo, W.; Welch, R.C.; Roy, S.; Fissell, W.H. Genome Engineering Renal Epithelial Cells for Enhanced Volume Transport Function. Cell Mol. Bioeng. 2020, 13, 17-26. [CrossRef] [PubMed]

88. Chen, H.-C.; Cheng, C.-Y.; Lin, H.-C.; Chen, H.-H.; Chen, C.-H.; Yang, C.-P.; Yang, K.-H.; Lin, C.-M.; Lin, T.-Y.; Shih, C.-M.; et al. Multifunctions of Excited Gold Nanoparticles Decorated Artificial Kidney with Efficient Hemodialysis and Therapeutic Potential. ACS Appl. Mater. Interfaces 2016, 8, 19691-19700. [CrossRef] [PubMed]

89. Murugesan, S.; Mousa, S.; Vijayaraghavan, A.; Ajayan, P.M.; Linhardt, R.J. Ionic Liquid-Derived Blood-Compatible Composite Membranes for Kidney Dialysis. J. Biomed. Mater. Res. Part B Appl. Biomater. 2006, 79B, 298-304. [CrossRef] [PubMed]

90. Reddy, A.R.N.; Reddy, Y.N.; Krishna, D.R.; Himabindu, V. Multi Wall Carbon Nanotubes Induce Oxidative Stress and Cytotoxicity in Human Embryonic Kidney (HEK293) Cells. Toxicology 2010, 272, 11-16. [CrossRef]

91. Herrera Sanchez, M.B.; Bruno, S.; Grange, C.; Tapparo, M.; Cantaluppi, V.; Tetta, C.; Camussi, G. Human Liver Stem Cells and Derived Extracellular Vesicles Improve Recovery in a Murine Model of Acute Kidney Injury. Stem Cell Res. Ther. $2014,5,124$. [CrossRef]

92. Cantaluppi, V.; Medica, D.; Mannari, C.; Stiaccini, G.; Figliolini, F.; Dellepiane, S.; Quercia, A.D.; Migliori, M.; Panichi, V.; Giovannini, L.; et al. Endothelial Progenitor Cell-Derived Extracellular Vesicles Protect from Complement-Mediated Mesangial Injury in Experimental Anti-Thy1.1 Glomerulonephritis. Nephrol. Dial. Transplant. 2015, 30, 410-422. [CrossRef]

93. Mollet, B.B.; Bogaerts, I.L.J.; van Almen, G.C.; Dankers, P.Y.W. A Bioartificial Environment for Kidney Epithelial Cells Based on a Supramolecular Polymer Basement Membrane Mimic and an Organotypical Culture System. J. Tissue Eng. Regen. Med. 2017, 11, 1820-1834. [CrossRef]

94. Zhao, H.; Li, L.; Zhan, H.; Chu, Y.; Sun, B. Mechanistic Understanding of the Engineered Nanomaterial-Induced Toxicity on Kidney. J. Nanomater. 2019, 2019, e2954853. [CrossRef]

95. Rana, S.V. Recent Advances on Renal Toxicity of Engineered Nanoparticles-A Review. J. Toxicol. Risk Assess. 2021, 7. [CrossRef]

96. Semashko, V.V.; Pudovkin, M.S.; Cefalas, A.-C.; Zelenikhin, P.V.; Gavriil, V.E.; Nizamutdinov, A.S.; Kollia, Z.; Ferraro, A.; Sarantopoulou, E. Tiny Rare-Earth Fluoride Nanoparticles Activate Tumour Cell Growth via Electrical Polar Interactions. Nanoscale Res. Lett. 2018, 13, 370. [CrossRef] 
97. Spyropoulos-Antonakakis, N.; Sarantopoulou, E.; Trohopoulos, P.N.; Stefi, A.L.; Kollia, Z.; Gavriil, V.E.; Bourkoula, A.; Petrou, P.S.; Kakabakos, S.; Semashko, V.V.; et al. Selective Aggregation of PAMAM Dendrimer Nanocarriers and PAMAM/ZnPc Nanodrugs on Human Atheromatous Carotid Tissues: A Photodynamic Therapy for Atherosclerosis. Nanoscale Res. Lett. 2015, 10, 210. [CrossRef]

98. Enciso, A.E.; Neun, B.; Rodriguez, J.; Ranjan, A.P.; Dobrovolskaia, M.A.; Simanek, E.E. Nanoparticle Effects on Human Platelets in Vitro: A Comparison between PAMAM and Triazine Dendrimers. Molecules 2016, 21, 428. [CrossRef]

99. Paradise, J. Regulating Nanomedicine at the Food and Drug Administration. AMA J. Ethics 2019, 21, 347-355. [CrossRef] [PubMed]

100. Institute of Medicine (US) Committee on the Public Health Effectiveness of the FDA 510(k) Clearance Process. Public Health Effectiveness of the FDA 510(k) Clearance Process: Measuring Postmarket Performance and Other Select Topics: Workshop Report; Wizemann, T., Ed.; National Academies Press: Washington, DC, USA, 2011; ISBN 978-0-309-16206-7.

101. Allon, I.; Ben-Yehudah, A.; Dekel, R.; Solbakk, J.-H.; Weltring, K.-M.; Siegal, G. Ethical Issues in Nanomedicine: Tempest in a Teapot? Med. Health Care Philos. 2017, 20, 3-11. [CrossRef] 